Union had been engaged long before Gorbachev's time. Now, there is even more tortuous discussion to be had. It is in everybody's interests that the republics should be tempted towards modesty in their reliance on nuclear weapons; countervailing self-restraint in Western Europe can only help.

And the timing is critical. In three years, the NPT will lapse unless its present members agree to soldier on. With all the shocks that system has suffered in the past few years, notably in Iraq, it is not too soon to begin working on the amendments to the treaty required for its perpetuation. Apart from the technical work needed on the supply of nuclear weapons, there are the strongest reasons to believe that a willingness by Britain and France to displace nuclear weapons from the heart of their national (as distinct from regional) defence would go a long way to cool tempers at the conference due in 1995.

\section{Russian roulette?}

Some parts of the Russian research establishment seem bent on firing those who spend too much time elsewhere.

General sympathy with the plight of the research community in what used to be the Soviet Union may not last as long as it will be needed, at least if some Russian reactions to public bankruptcy become widespread. There are two spheres in which money problems bite. Hard currency, called 'currency' in the vernacular, has virtually disappeared from the research enterprise, with the result that reagents and journals previously bought from outside have simply become unobtainable. And, now that the printing presses have been halted (or are manufacturing rubles less quickly), research institutes are unable adequately to support their own members. For the past three years, most of them have been free to adjust individual salaries by the use of a proportion of whatever income they have from outside. Now, some of them appear to be turning to intellectual cannibalism of a disturbing kind.

Researchers able to make what are called 'business trips' abroad have always been enviously regarded in the Soviet Union. In the bad old days, the frequency and duration of such visits was more a mark of indulgence and patronage than merit, but that has mercifully changed in the past few years. But now there is a risk that seriously intended and welcome visits to laboratories elsewhere will dry up. That, at least, may be the consequence of the decision by some institutes of the Russian Academy of Sciences at Novosibirsk that researchers who spend three months or more at an overseas laboratory may be required to pay for the privilege with their jobs. They may be sacked.

A more efficient way to encourage mediocrity could hardly be devised. The people who trickle overseas in these competitive times are the brightest and the best; ideally they are also young. It is in everybody's interest, and not least that of the Russian research enterprise itself, that they should be welcomed back to posts enjoying more, and not less, of what little security the new republics can offer. It is to be hoped that the Novosibirsk recipe will not be followed generally - and that it will abandoned even there.

\section{Psychics in court}

MR Uri Geller, the spoon-bender (who is still among us, but less obtrusively than in the past) seems to have stumbled into an awkward dilemma. As part of the trial of a legal action for libel against Mr James ('the Amazing') Randi, a Florida Court has now decided that Geller must perform a demonstration of his psychic powers. Only then, the court seems to have argued, will it be possible fairly to assess Randi's disputed allegations that Geller's powers are not out of the ordinary. As part of the discovery process, the court requires that Geller's demonstration should be recorded by video camera.

The occasion should have a significance extending beyond the suit being tried in Florida. Geller is not, of course, the only one to claim psychic powers. There is an army of astrologers and a batallion of faith-healers whose claims are similarly disputed by rational people. Sadly, their claims on public attention are too often untested in any objective way. Indeed, a degree of mystery seems inseparable from their success; only a few weeks ago, Geller told the Israeli newspaper Yediot Achronot, "I prefer that no one should ever know if I am real or not. It's better that there should be some controversy surrounding me." The truth of that assertion is easily understood. Whatever the validity of the psychics' claims, their use of them is usually inseparable from show-business of a kind. Unintentionally, the Florida courts have now struck a blow for objectivity by commanding a test of Geller's psychic powers. In the public interest, it is earnestly to be hoped that he takes part in the demonstration.

\section{Yale retrenches}

YALE University has taken a bold step in its announced intention to face fiscal reality by cutting back some academic departments and eliminating others (see p. 288). For years US universities, whose science departments were generously funded by government grants that also provided substantial overhead costs to the general university administration, have lived as if money were no object in the pursuit of education and knowledge. Now reality has struck. Yale is not the first university to talk about eliminating whole departments (in this case linguistics, operations research and an institute for social and policy studies), but it is the most prominent. So far. Yale is at the forefront in recognizing the urgency of making hard choices and it is to be commended for doing so. It is to be hoped that intramural politics will not prevent Yale from doing what is, in principle, necessary and altogether sensible. 